
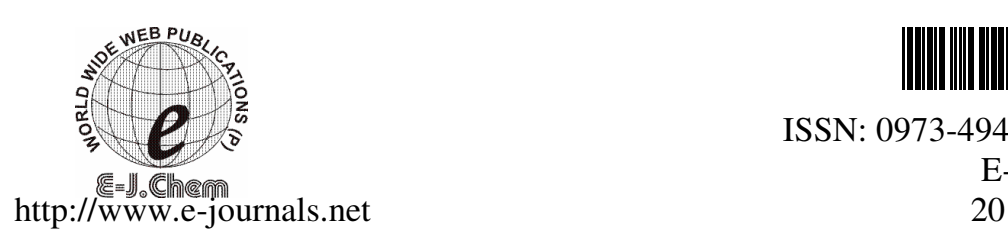

ISSN: 0973-4945; CODEN ECJHAO

E-Journal of Chemistry

2010, 7(S1), S419-S427

\title{
Adsorption Kinetics for the Removal of Fluoride from Aqueous Solution by Activated Carbon Adsorbents Derived from the Peels of Selected Citrus Fruits
}

\author{
CH. CHAKRAPANI*, CH. SURESH BABU, \\ K.N.K. VANI and K. SOMASEKHARA RAO \\ Department of Chemistry \\ Acharya Nagarjuna University-Nuzvid Campus, Nuzvid-521201, A.P., India \\ chakrapanichallari@yahoo.com
}

Received 20 May 2009; Accepted 15 July 2009

\begin{abstract}
Activated carbons (ACs) were prepared from the peels of Citrus documana, Citrus medica and Citrus aurantifolia fruits. Adsorption of fluoride onto these activated carbons was investigated. Effect of contact time in the removal of fluoride from aqueous solution at neutral $\mathrm{pH}$ was studied. Five kinetic models; the pseudo first- and second-order equations, intraparticle diffusion, pore diffusion and the Elovich equation, were selected to follow adsorption process. Adsorption of fluoride onto adsorbents could be described by pseudo second-order equation. Kinetic parameters; rate constants, equilibrium adsorption capacities and correlation coefficients, for each kinetic equation were calculated and discussed. The good fitting of kinetic data to pore diffusion and Elovich equations indicate that pore diffusion plays a vital role in controlling the rate of the reaction.
\end{abstract}

Keywords: Adsorption, Activated carbons, Adsorption kinetics, Citrus fruits.

\section{Introduction}

Fluoride is found in all natural waters at some concentration. Long term exposure to higher levels of fluoride $(>1.5 \mathrm{ppm})$ in drinking water leads to serious health problems ${ }^{1,2}$ like skeletal fluorosis, brain damage, osteoporosis, thyroid disorder and cancer $^{3,4}$. Various defluoridation technologies based on the principle of precipitation ${ }^{5}$, ion exchange ${ }^{6}$ and electrochemical ${ }^{7}$ methods have been proposed to remove excess fluoride in drinking water and industrial effluents. Among various methods, adsorption is a suitable technique. The application of activated carbons in the adsorptive removal of inorganics from water has been the subject matter of numerous investigators. Activated carbon prepared from rice straw ${ }^{8}$, bio-materials ${ }^{9}$, alumina impregnated carbons ${ }^{10,11}$ and waste carbon slurry ${ }^{12}$ are different 
adsorbents used for defluoridation process. In the present study, activated carbons (ACs) prepared from the peels of some selected citrus fruits are used in removing fluoride from aqueous solution with the aim of understanding the kinetics of the adsorption process at neutral $\mathrm{pH}$.

One of the most important factors in designing an adsorption system is predicting the rate at which adsorption takes place, referred to the 'kinetics of sorption'. In adsorption processes, the selection of an adsorbent, its configuration and attainment of equilibrium are related to the 'rate-limiting' process. An understanding of the rate-limiting step will greatly aid in deciding the time of contact to be allowed between the sorbent and sorbate. So, to properly interpret the experimental data, it is necessary to determine the rate-limiting step for the adsorption process, which governs the overall removal rate and mechanisms of sorption. There are essentially three consecutive steps in the adsorption of materials from solution by porous adsorbents, namely bulk diffusion, film diffusion and pore diffusion. Any of these steps can be 'rate-limiting' in adsorption. Generally, both pore diffusion and film diffusion were considered to be the major factors controlling rates of sorption from solution by porous adsorbents. As they act in series, the slower of the two, was regarded as ratelimiting in an adsorption process ${ }^{13,14}$.

\section{Experimental}

The activated carbon adsorbents viz., NCDC, NCMC and NCAC were prepared form the peels of Citrus documana, Citrus medica and Citrus aurantifolia fruits respectively. The peels of selected citrus fruits were obtained from a local fruit stall at Eluru, Andhra Pradesh. The peels were dried, crushed and washed thoroughly with de-ionized water to remove adhering dirt. They were air dried in an oven at $100-120{ }^{\circ} \mathrm{C}$ for $24 \mathrm{~h}$. After drying, they are carbonized at $500{ }^{\circ} \mathrm{C}$ in a uniform nitrogen flow and subjected to liquid phase oxidation with $0.1 \mathrm{~N} \mathrm{HNO}_{3}$ (analytical grade). Further they were washed with double-distilled water to remove the excess acid and dried at $150{ }^{\circ} \mathrm{C}$ for $12 \mathrm{~h}$.

The stock solution of $100 \mathrm{mg} \mathrm{L}^{-1}$ fluoride was prepared by dissolving $221 \mathrm{mg}$ of anhydrous $\mathrm{NaF}$ in $1 \mathrm{~L}$ of distilled water. Test solution of $5 \mathrm{mg} \mathrm{L}^{-1} \mathrm{~F}^{-}$was prepared from fresh stock solution. All the experiments were carried out in $250 \mathrm{~mL}$ conical flasks with 100 $\mathrm{mL}$ test solution at room temperature $\left(25 \pm 2{ }^{\circ} \mathrm{C}\right)$. The flasks, along with test solution and $1 \mathrm{~g}$ of the adsorbent at neutral $\mathrm{pH}$, were shaken in horizontal shaker at $120 \mathrm{rpm}$ to study the equilibration time (5-50 min) for maximum adsorption of fluoride and to know the kinetics of adsorption process. At the end of the desired contact time, the samples were filtered using Whatman no. 42 filter paper and the filtrate was analyzed for residual fluoride concentration by SPADNS method, described in the standard methods of examination of water and wastewater ${ }^{15}$.

\section{Results and Discussion}

\section{Effect of contact time}

A plot between time $t(\mathrm{~min})$ and amount of fluoride adsorbed with time $q_{t}\left(\mathrm{mg} \mathrm{g}^{-1}\right)$ is shown in Figure 1. As agitation time increases, fluoride removal also increases initially, but then gradually approaches a more or less constant value, denoting the attainment of equilibrium. Similar trend was observed by other workers during adsorption of fluoride onto protonated chitosan beads ${ }^{16}$. With respect to contact time, NCDC, NCMC and NCAC reached saturation after 30, 35 and 35 min respectively, which were fixed as their optimum contact times. Among the three sorbents, NCDC exhibits higher adsorption capacity followed by NCMC and NCAC. 


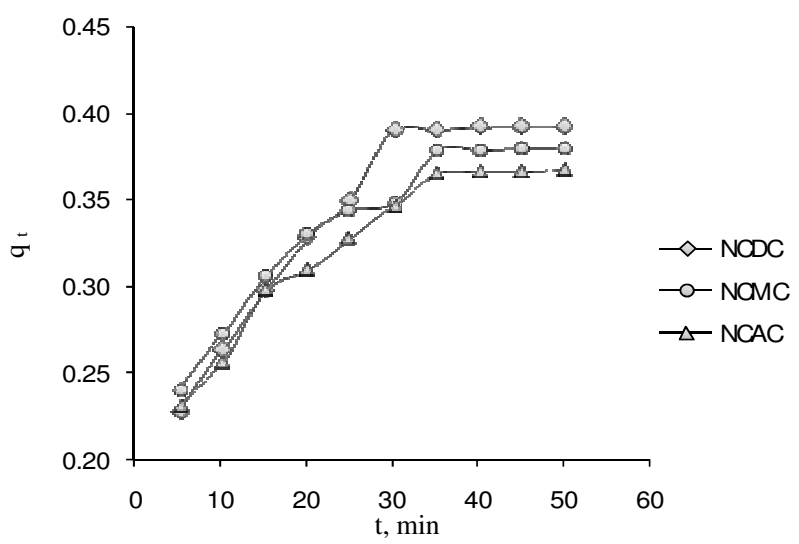

Figure 1. Effect of contact time on adsorption of fluoride onto NCDC, NCMC and NCAC

\section{Fitness of the kinetic models}

The best-fit among the kinetic models was assessed by the squared sum of errors (SSE) values. It is assumed that the model which gives the lowest SSE values is the best model for the particular system ${ }^{17,18}$. The SSE values were calculated by the equation,

$$
S S E=\sum \frac{\left(q e_{(\operatorname{expt.})}-q e_{(c a l .)}\right)^{2}}{q_{2} e_{(\exp t .)}}
$$

Where $q_{\text {e(expt.) }}$ and $q_{\mathrm{e}(\mathrm{cal}) \text {.) }}$ are the experimental sorption capacity of fluoride $\left(\mathrm{mg} \mathrm{g}^{-1}\right)$ at equilibrium time and the corresponding value that is obtained from the kinetic models. SSE values and various kinetic parameters for all the kinetic models were calculated and are summarized in Table 1.

\section{Adsorption kinetics}

Five simplified kinetic models namely pseudo first-order, pseudo second-order, Weber and Morris intraparticle diffusion model, Bangham's pore diffusion model and Elovich equations have been discussed to identify the rate and kinetics of sorption of fluoride onto NCDC, NCMC and NCAC.

\section{Pseudo first-order model}

The Lagergren's rate equation is one of the most widely used rate equation to describe the adsorption of adsorbate from the liquid phase ${ }^{19,20}$. The linear form of pseudo first-order rate expression of Lagergren is given as

$$
\log \left(q_{e}-q_{t}\right)=\log q_{e}-\frac{k_{1} t}{2.303}
$$

Where, $q_{e}$ and $q_{t}$ are the amounts of fluoride adsorbed on adsorbent $\left(\mathrm{mg} \mathrm{g}^{-1}\right)$ at equilibrium and at time $t(\mathrm{~min})$, respectively, and $k_{l}$ is the rate constant of pseudo first-order kinetics. Figure 2(a) shows the plots of linearized form of pseudo first-order kinetic model for the three sorbents. The plots were found linear with good correlation coefficients $(>0.9)$ indicating the applicability of pseudo first-order model in the present study. The pseudo first-order rate constant $\left(k_{l}\right)$ and $q_{e(c a l)}$ values were determined for each adsorbent from the slope and the intercept of corresponding plot (Figure 2(a)) and are listed in Table 1. 

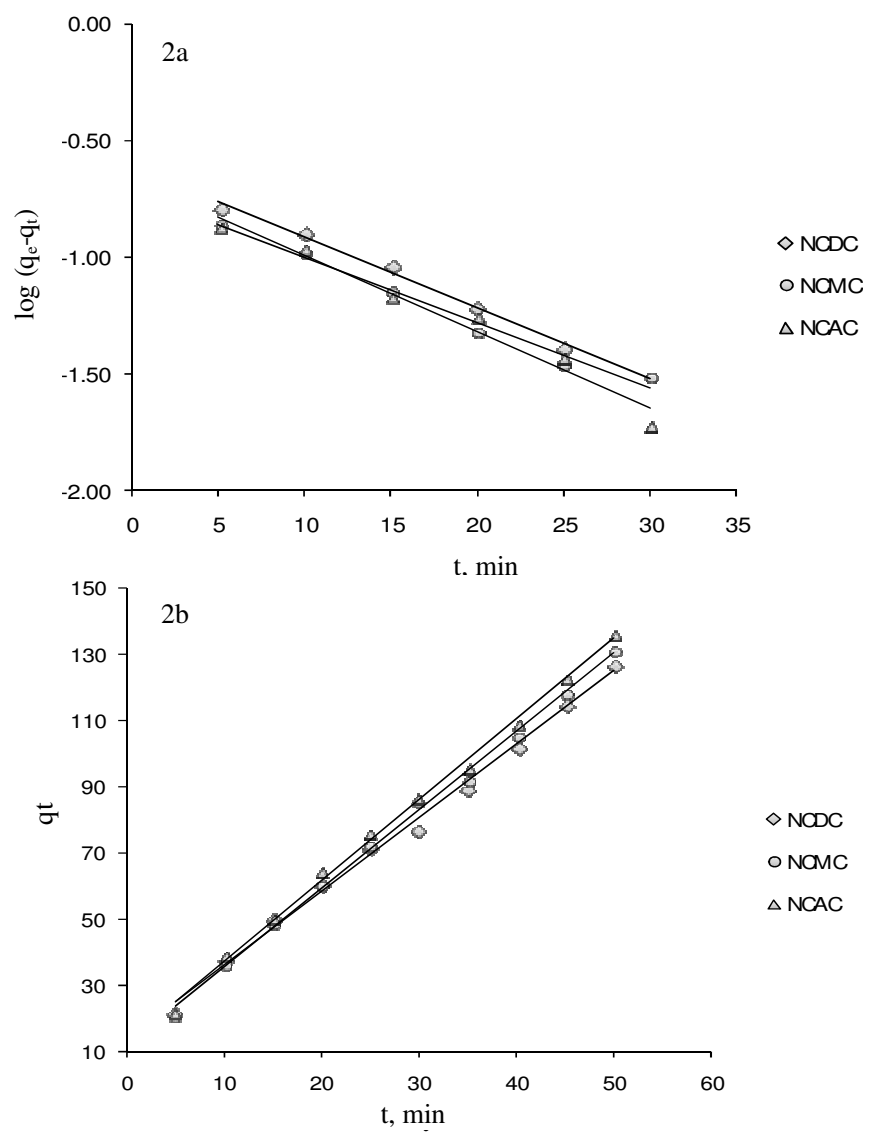

Figure 2. Kinetic modeling of adsorption of fluoride onto NCDC, NCMC and NCAC (a) pseudo first-order; (b) pseudo second-order

\section{Pseudo second-order model}

The adsorption kinetics was also described as pseudo-second order process using the following equation ${ }^{21}$,

$$
\frac{t}{q_{t}}=\frac{1}{k_{s} q_{e}{ }^{2}}+\left(\frac{1}{q_{e}}\right) t
$$

Where, $q_{e}$ and $q_{t}$ have the same meaning as mentioned previously and $k_{2}$ is the rate constant for the pseudo second-order kinetics. The plots of $t / q_{t}$ versus $t$ for the three adsorbents are shown in Figure 2(b). The values of $\mathrm{q}_{\mathrm{e}(\mathrm{cal}) \text { ) }}$ and $k_{2}$ were determined for each adsorbent from the slope and intercept of the corresponding plot and are compiled in Table 1.

The correlation co-efficient $\left(\mathrm{R}^{2}\right)$ values for pseudo second-order adsorption model have high values, 0.9946, 0.9971 and 0.997 for NCDC, NCMC and NCAC respectively. Comparatively in each case, the $\mathrm{R}^{2}$ value is higher than that of pseudo first-order model. The lower SSE values for pseudo second order model also indicate that the adsorption kinetics of fluoride onto NCDC, NCMC and NCAC can be better described by pseudo second order model. Similar phenomenon has observed in the literature for the adsorption of fluoride on various adsorbents ${ }^{8,22-24}$. 
Table 1. Comparison of pseudo first-order, pseudo second-order, Weber and Morris, Bangham's and Elovich models parameters and calculated $q_{\text {e(cal.) }}$ and experimental $q_{\text {e(expt.) }}$ values at $5 \mathrm{mg} \mathrm{L}^{-1}$ fluoride concentration.

\begin{tabular}{|c|c|c|c|c|c|c|}
\hline \multicolumn{7}{|c|}{ Pseudo first-oder } \\
\hline Adsorbent & $\begin{array}{l}\mathrm{q}_{\text {e(expt.-. }} \\
\mathrm{mg} \mathrm{g}_{\mathrm{g}}\end{array}$ & $\begin{array}{l}\mathrm{k}_{1} \times 10^{-1}, \\
\mathrm{~min}^{-1}\end{array}$ & $\mathrm{q}_{\mathrm{e}(\mathrm{Cal}) \mathrm{g}}$ & SSE & $\mathrm{R}^{2}$ & \\
\hline NCDC & 0.3910 & 0.6955 & 0.2447 & 0.14000 & 0.9900 & \\
\hline NCMC & 0.3800 & 0.6425 & 0.1898 & 0.25053 & 0.9824 & \\
\hline NCAC & 0.3660 & 0.7554 & 0.217 & 0.16573 & 0.9692 & \\
\hline \multicolumn{7}{|c|}{ Pseudo second-oder } \\
\hline Adsorbent & $\begin{array}{l}\text { Ye(expt.-', } \\
\mathrm{mg} \mathrm{g}^{-1}\end{array}$ & $\mathrm{~g} \mathrm{mg}^{-1} \min ^{-1}$ & $\begin{array}{l}\text { Ye(Cal. })_{1} \\
\mathrm{mg} \mathrm{g}^{-1}\end{array}$ & SSE & $\mathrm{R}^{2}$ & \\
\hline NCDC & 0.3910 & 3.5065 & 0.4503 & 0.02300 & 0.9946 & \\
\hline NCMC & 0.3800 & 4.7403 & 0.4214 & 0.01187 & 0.9971 & \\
\hline NCAC & 0.3660 & 4.6028 & 0.4098 & 0.01432 & 0.9970 & \\
\hline \multicolumn{7}{|c|}{ Intraparticle diffusion } \\
\hline Adsorbent & $\begin{array}{l}\mathrm{q}_{\text {e(expt.). }} \text {, } \\
\mathrm{mg} \mathrm{g}^{-1}\end{array}$ & $\begin{array}{c}\mathrm{k}_{\mathrm{ip}} \times 10^{-1}, \\
\mathrm{mg} \mathrm{g}^{-1} \min ^{-0.5}\end{array}$ & $\begin{array}{l}\left.\mathrm{q}_{\mathrm{e}(\mathrm{Cal} .)}\right)_{1} \\
\mathrm{mg} \mathrm{g}^{-1}\end{array}$ & SSE & $\mathrm{R}^{2}$ & \\
\hline NCDC & 0.3910 & 0.4870 & 0.3807 & 0.00069 & 0.9867 & \\
\hline NCMC & 0.3800 & 0.3620 & 0.3768 & 0.00007 & 0.9815 & \\
\hline NCAC & 0.3660 & 0.3640 & 0.3643 & 0.00002 & 0.9896 & \\
\hline \multicolumn{7}{|c|}{ Pore diffusion } \\
\hline Adsorbent & $\begin{array}{l}\mathrm{q}_{\text {e(expt.), }} \\
\text { mg g }\end{array}$ & $\begin{array}{c}\mathrm{k}_{0}, \\
\mathrm{~mL}, \mathrm{~g} \mathrm{~L}^{-1}\end{array}$ & $\begin{array}{l}\mathrm{q}_{\mathrm{e}(\mathrm{Cal} .)},{ }^{-1} \\
\mathrm{mg} \mathrm{g}^{-1}\end{array}$ & SSE & $\mathrm{R}^{2}$ & $\alpha$ \\
\hline NCDC & 0.3910 & 3.0199 & 0.3638 & 0.00484 & 0.9663 & 0.2696 \\
\hline NCMC & 0.3800 & 3.4801 & 0.3660 & 0.00136 & 0.9805 & 0.2198 \\
\hline NCAC & 0.3660 & 3.2681 & 0.3528 & 0.00130 & 0.9768 & 0.2268 \\
\hline \multicolumn{7}{|c|}{ Elovich equation } \\
\hline Adsorbent & $\begin{array}{l}\mathrm{q}_{\text {e(expt.), }} \\
\mathrm{mg} \mathrm{g}_{\mathrm{g}}\end{array}$ & $\beta$ & $\begin{array}{l}\mathrm{qe}_{\mathrm{e}(\mathrm{Cal}),}, \\
\mathrm{mg} \mathrm{g}^{-1}\end{array}$ & SSE & $\mathrm{R}^{2}$ & A \\
\hline NCDC & 0.3910 & 12.2549 & 0.3792 & 0.00091 & 0.9592 & 0.0081 \\
\hline NCMC & 0.3800 & 15.0376 & 0.3458 & 0.00810 & 0.9791 & 0.0134 \\
\hline NCAC & 0.3660 & 15.1286 & 0.3329 & 0.00818 & 0.9743 & 0.0113 \\
\hline
\end{tabular}

\section{Intraparticle diffusion}

Rate of sorption is frequently used to analyze nature of the 'rate-controlling step' and the use of the intraparticle diffusion model has been greatly explored in this regard which is represented by the following Weber and Morris equation ${ }^{20}$.

$$
q_{t}=k_{i p} t^{1 / 2}+C
$$

Where, $C$ is the intercept, related to the thickness of the boundary layer and $k_{i p}$ is the intraparticle diffusion rate constant. According to this model, if adsorption of a solute is controlled by the intraparticle diffusion process, a plot of $q_{t}$ versus $t^{1 / 2}$ gives a straight line. Weber and Morris plots of $q_{t}$ versus $t^{1 / 2}$ are shown in Figures 3(a), 3(b) and 3(c) for NCDC, NCMC and NCAC respectively. It is evident from the plots that there are two separate stages; first linear portion (Stage I) and second curved path followed by a plateau (Stage II). In Stage I, nearly $50 \%$ of fluoride was rapidly up taken by carbon adsorbents within $5 \mathrm{~min}$. This is attributed to the immediate utilization of the most readily available adsorbing sites on the adsorbent surfaces. In Stage II, very slow diffusion of adsorbate from surface site into the innerpores is observed. Thus initial portion of fluoride adsorption by carbon adsorbents may be governed by the initial intraparticle transport of fluoride controlled by surface diffusion process and later part is controlled by pore diffusion. Similar dual nature with initial linear and then plateau were found in the literature ${ }^{8,25}$. 
Though intraparticle diffusion renders straight lines with correlation co-efficients $(>0.98)$ for all the three sorbents, the intercept of the line fails to pass through the origin in each case may be due to difference in the rate of mass transfer in the initial and final stages of adsorption ${ }^{26}$ and indicates some degree of boundary layer control which implies that intraparticle diffusion is not only the rate controlling step ${ }^{19}$. The data were further used to learn about the slow step occurring in the present adsorption system using pore diffusion model.
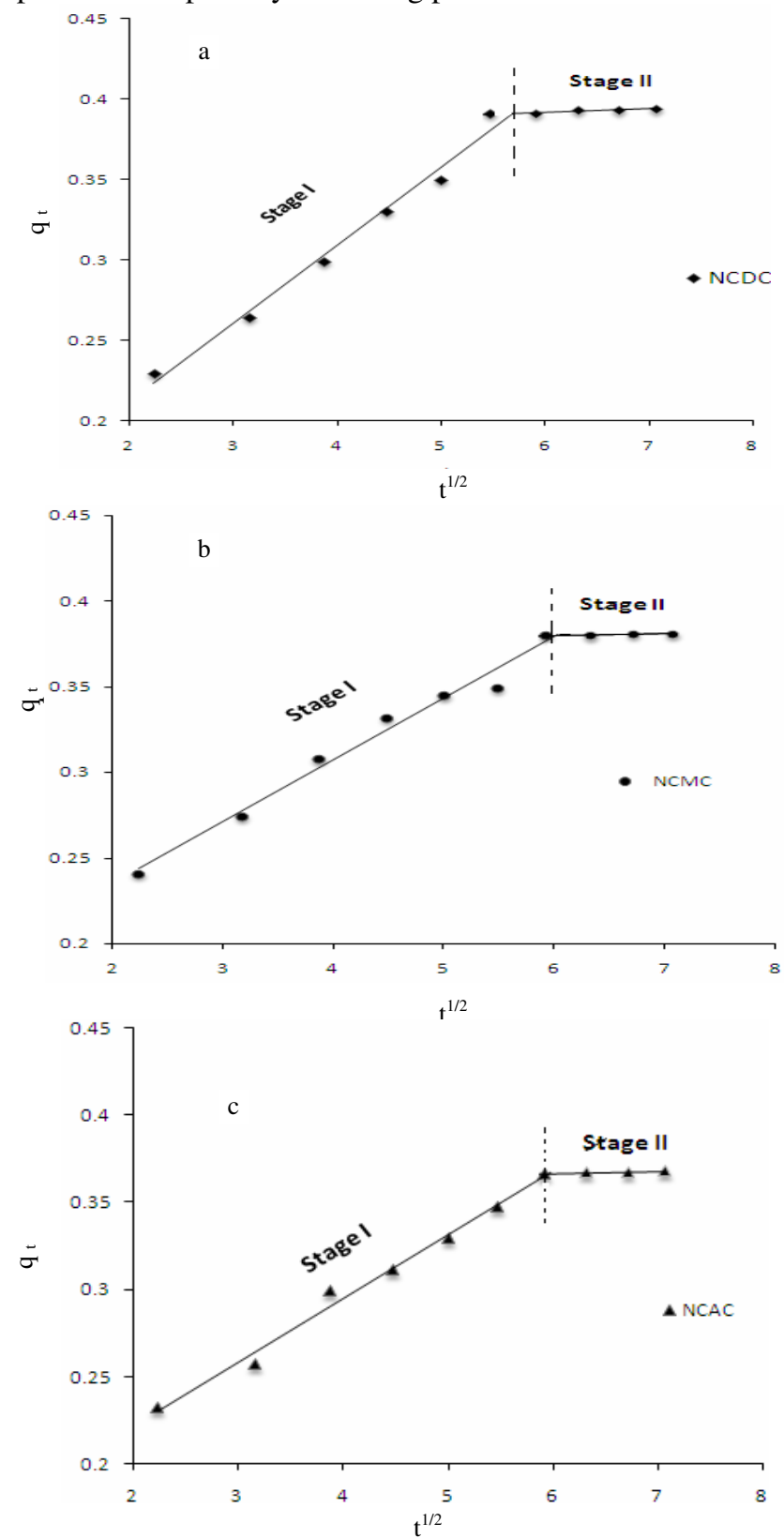

Figure 3. Intraparticle diffusion plots of (a) NCDC; (b) NCMC and (c) NCAC 


\section{Pore diffusion model (Bangham's model)}

Bangham's equation $^{27}$ (Equation (5)) has been used to describe pore diffusion during adsorption process.

$$
\log \log \left(\frac{C_{i}}{C_{i}-q_{t} m}\right)=\log \left(\frac{k_{O}}{2.303 V}\right) \propto \log t
$$

Where, $C_{i}$ is the initial concentration of the adsorbate in solution $\left(\mathrm{mg} \mathrm{L}^{-1}\right), V$ is the volume of the solution $(\mathrm{mL}), \mathrm{m}$ is the weight of adsorbent $\left(\mathrm{g} \mathrm{L}^{-1}\right), \mathrm{q}_{\mathrm{t}}\left(\mathrm{mg} \mathrm{g}^{-1}\right)$ is the amount of adsorbate retained at time $t$ and $\alpha$ (less than 1) and $k_{0}$ are the constants. As such $\log \log \left[C_{i} /\left(C_{i}-q_{t} m\right)\right]$ was plotted against $\log (t)$ in Figure 4 for all the three sorbents. The plot was found to be linear for each adsorbent with good correlation co-efficient $(>0.9)$ indicating that kinetics confirmed to Bangham's equation and therefore the adsorption of fluoride onto NCDC, NCMC and NCAC was pore diffusion controlled. Similar trend was observed in the literature for the adsorption of fluoride onto waste carbon slurry $^{12}$.

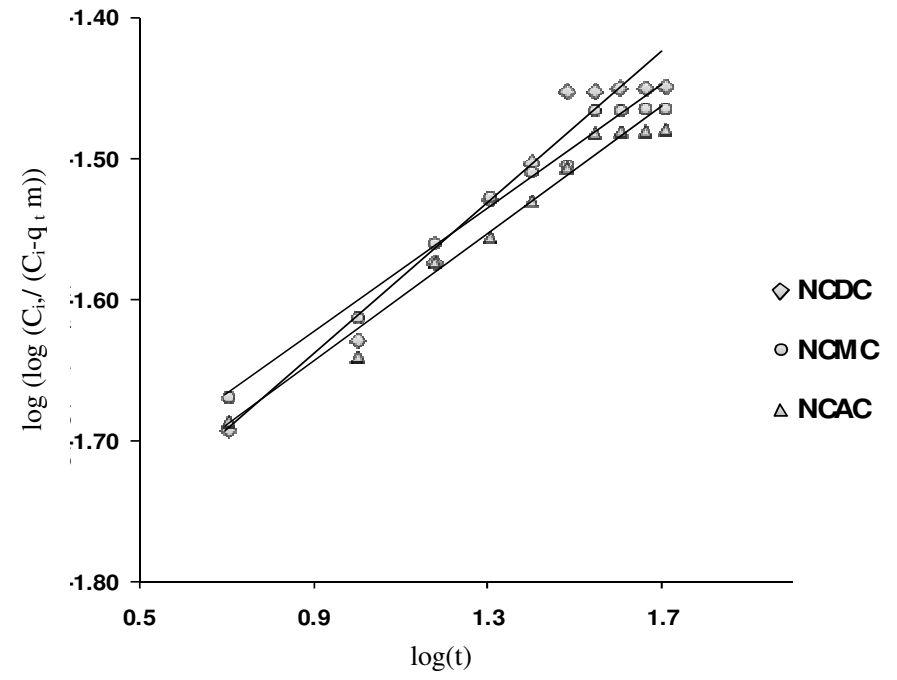

Figure 4. Pore diffusion plots of NCDC, NCMC and NCAC

\section{Elovich equation}

The Elovich equation ${ }^{28}$ is given as follows:

$$
q t=\frac{1}{\beta} \ln (\alpha \beta t)=\frac{1}{\beta} \ln (\alpha \beta t)+\frac{1}{\beta} \ln (t)
$$

Where $\alpha\left(\mathrm{mg} \mathrm{g}^{-1} \mathrm{~min}^{-1}\right)$ is the initial sorption rate and the parameter $\beta\left(\mathrm{g} \mathrm{mg}^{-1}\right)$ is related to the extent of surface coverage and activation energy for chemisorption. The kinetic results will be linear on a $q_{t}$ versus $\ln (t)$ plot (Figure 5), if the results follow an Elovich equation. It was suggested that diffusion accounted for the Elovich kinetics pattern ${ }^{29}$; conformation to this equation alone might be taken as evidence that the rate-determining step is diffusion in nature $^{30}$ and that this equation should apply at conditions where desorption rate can be neglected ${ }^{31}$. The kinetic curve of sorption demonstrated good fitting with the model $\left(R^{2}>0.9\right)$ which may indicate that the diffusional rate-limiting is more prominent in fluoride sorption by NCDC, NCMC and NCAC. 


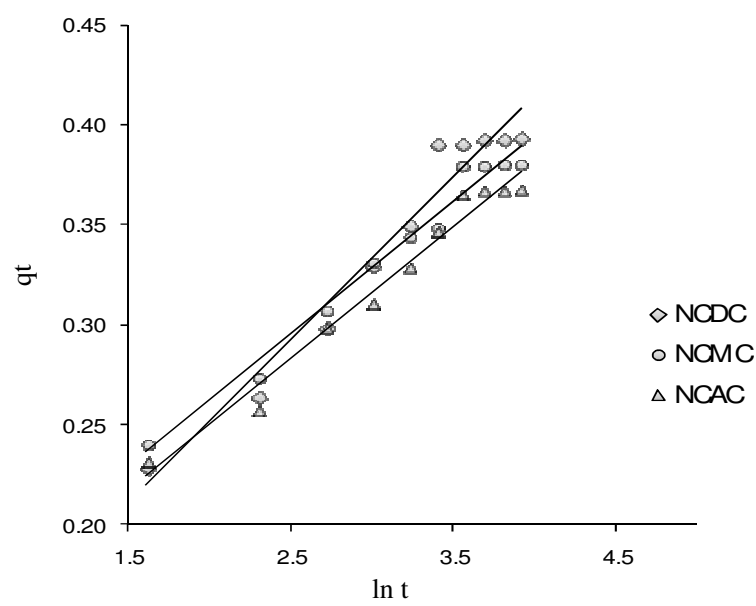

\section{Conclusion}

Figure 5. Elovich equation plots of NCDC, NCMC and NCAC

The fitting of the kinetic data demonstrate that the dynamics of sorption could be better described by pseudo second-order model indicating a chemisorptive rate-limiting for all the three adsorbents, NCDC, NCMC and NCAC. Though the plots of intraparticle diffusion renders straight lines with good correlation co-efficients, they fail to pass through origin in each case. This suggests that the process is 'complex' with more than one mechanism limiting the rate of sorption. The good fitting of the kinetic data, to Bangham's and Elovich equations indicates that pore diffusion plays a vital role in controlling the rate of reaction.

\section{References}

1. Susheela A K, Curr Sci., 1999, 77, 1250-1256.

2. WHO, Fluorine and fluorides; Geneva, Switzerland; World Health Organization, Distribution and Sales Service, Environmental Health Criteria Number 36, 1984.

3. Chinoy N J, Indian J Environ Toxicol., 1991, 1(1), 17-32.

4. Harrison P T C, J Fluor Chem., 2005, 126, 1448-1456.

5. Bulusu K R, Sundaresan B B, Pathak B N, Nawlakhe W G, Kulkarni D N and Thergoankar V P, J Inst Eng Environ Eng Div., 1979, 60, 1-25.

6. Popat K M, Anand P S and Dasare B D, React Polym., 1994, 23, 23-32.

7. Adhikary S K, Tipnis U K, Harkare W P and Govindan K P, Desalination, 1989, 71(3), 301-312.

8. Daifullah A A M, Yakout S M and Elreefy S A, J Hazard Mater., 2007, 147, 633-643.

9. Somasekhara Rao K, Asian J Chem Environ Res., 2008, 1, 1-12.

10. Leyva Ramos R, Ovalle-Turrubiartes J and Sanchez-Castillo M A, Carbon, 1999, 37(4), 609-617.

11. Li Y H, Wang S, Cao A, Zhao D, Zhang X, Xu C, Luan Z, Ruan D, Liang J, Wu D and Wei B, Chem Phys Lett., 2001, 350, 412-416.

12. Gupta V K, Ali I and Saini V K, Water Res., 2007, 41, 3307-3316.

13. Benefield D L, Judkins J F and Weand B L, Process Chemistry for Water and Wastewater Treatment, Prentice-Hall Inc., Englewood Cliffs, NJ, 1982.

14. Weber Jr. W J, Adsorption theory, concepts and models, in: F.L. Slejko (Ed.), Adsorption Theory, Marcel Deckker, NY, 1985. 
15. Standard Methods for the Examination of Water and Wastewater, APHA, AWWA, WEF, Washington, DC, 1995.

16. Viswanathan N, Sairam Sundaram C and Meenakshi S, J Hazard Mater., 2009, 161(1), 423-430.

17. Meeenakshi S and Viswanathan N, J Colloid Interf Sci., 2007, 308, 438-450.

18. Ho Y S, Ng J C Y and McKay G, Sep Purif Methods, 2000, 29, 189-232.

19. Lagergren S and Svenska K, About the Theory of So-Called Adsorption of Soluble Substances, Vetenskapsakad Handl.1898, 24(2), 1- 39.

20. Weber Jr. W J and Morris J C, J Sanit Eng Div., 1963, 89, 31-59.

21. Ho Y S and McKay G, Process Biochem., 1999, 34, 451-465.

22. Simons R, Desalination, 1993, 89(3), 325-341.

23. Sivasamy A, Singh K P, Mohan D and Maruthamuthu M, J Chem Technol Biotechnol., 2001, 76(7), 717-722.

24. Liao X P and Shi B, Environ Sci Technol., 2005, 39(12), 4628-4632.

25. Kumar E, Bhatnagar A, Ji M, Jung W, Lee S H, Kim S J, Lee G, Song H, Choi J Y, Yang J S and Jeon B H, Water Res., 2008, 43(2), 490-498.

26. Panday K K, Prasad G and Singh V N, Environ Tech Lett., 1986, 50(7), 547-554.

27. Aharoni C and Ungarish M, J Chem Soc Faraday Trans I, 1977, 73(3), 456-464.

28. Zhang J and Stanforth R, Langmuir, 2005, 21(7), 2895-2901.

29. Aharoni C, Sparks D L, Levinson S and Revina I, Soil Sci Soc Am J., 1991, 55, 1307-1312.

30. Pavlatou A and Polyzopouls N A, Eur J Soil Sci., 1988, 39, 425-436.

31. Rudzinksi W and Panczyk P, in: Schwarz J A, Contescu C I, (Eds.,) Surfaces of Nanoparticles and Porous Materials, Dekker, New York, 1998, p. 355. 


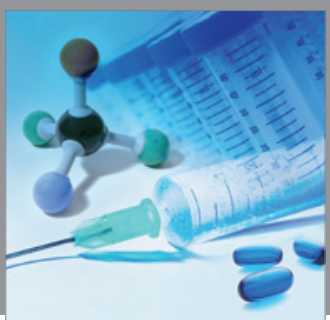

International Journal of

Medicinal Chemistry

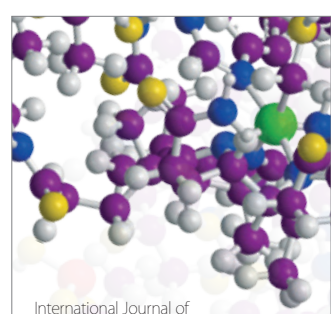

Carbohydrate Chemistry

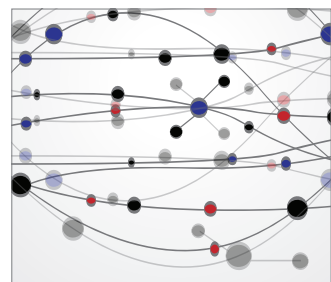

The Scientific World Journal
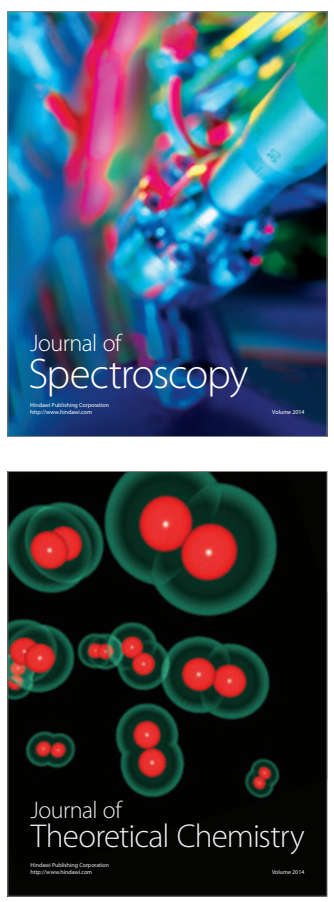
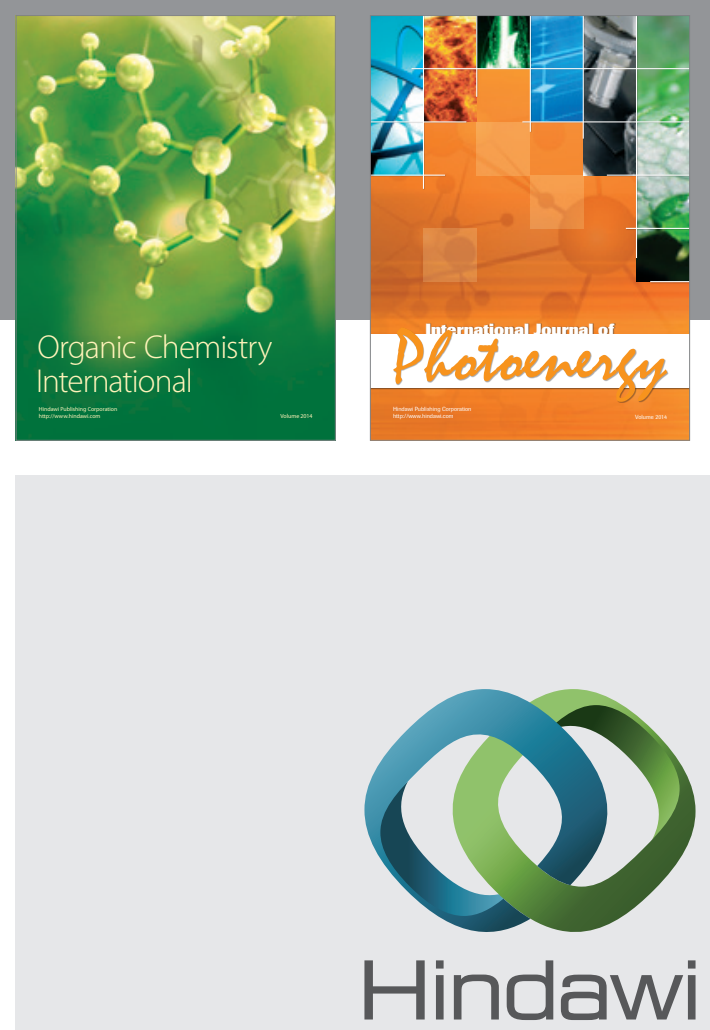

Submit your manuscripts at

http://www.hindawi.com
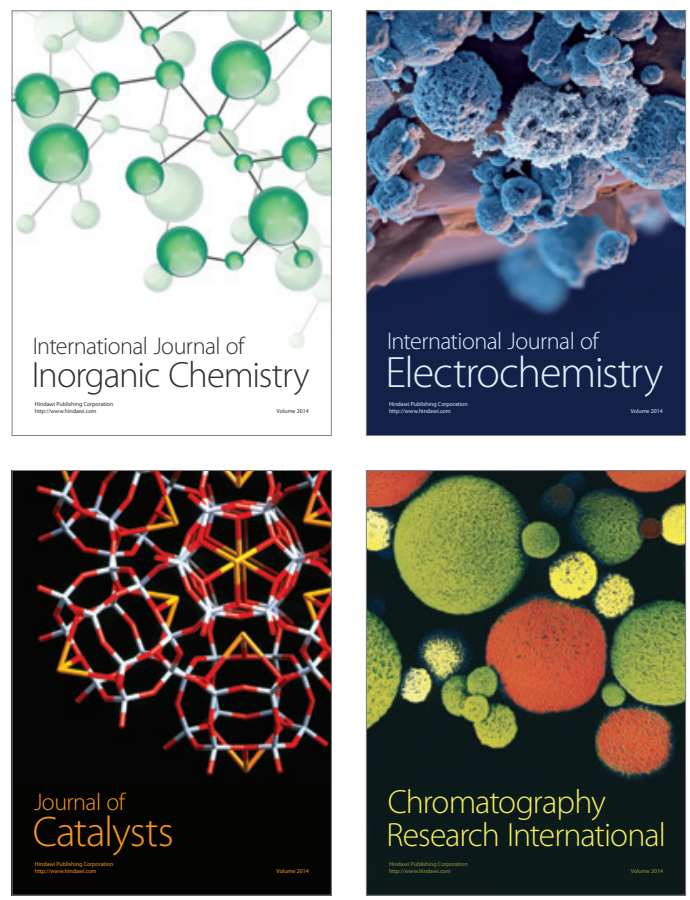
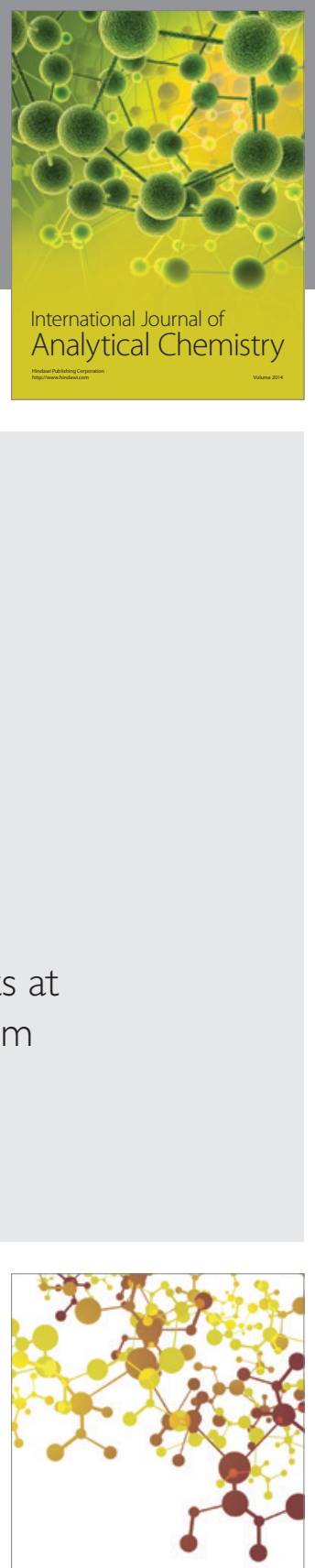

Journal of

Applied Chemistry
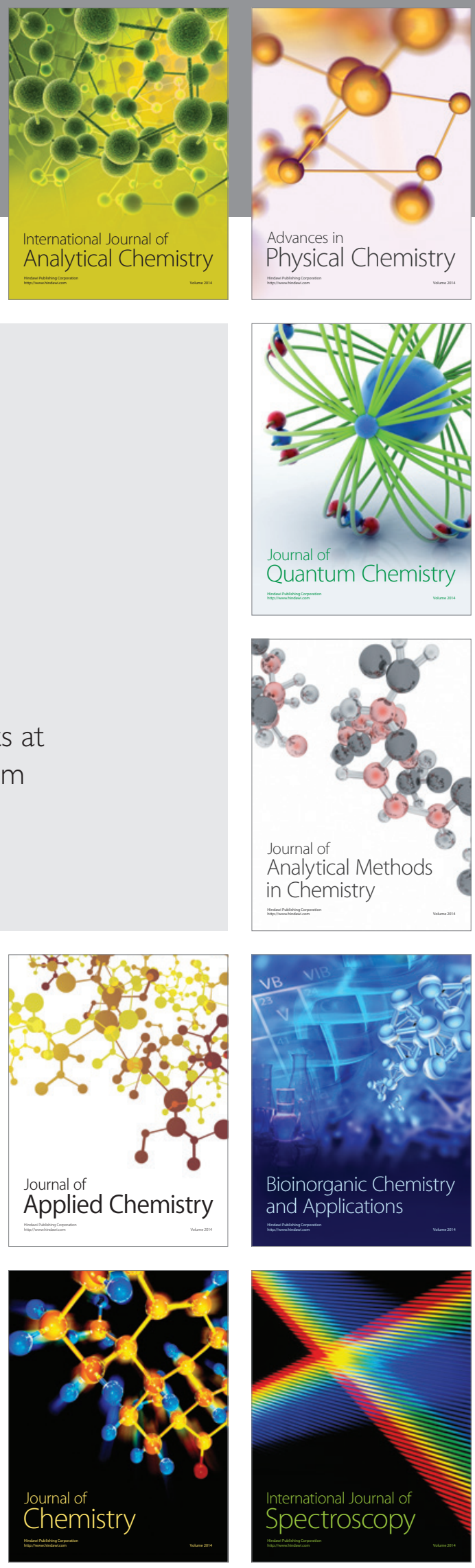